\title{
Occurrence, behavior and removal of typical substituted and parent polycyclic aromatic hydrocarbons in a biological wastewater treatment plant
}

\author{
Meng Qiao ${ }^{a, b}$, Weixiao Qi ${ }^{a}$, Huijuan Liu $^{a}$, Jiuhui Qu ${ }^{a, *}$ \\ ${ }^{a}$ State Key Laboratory of Environmental Aquatic Chemistry, Research Center for Eco-Environmental Sciences, \\ Chinese Academy of Sciences, Beijing 100085, China \\ ${ }^{\mathrm{b}}$ University of Chinese Academy of Sciences, Beijing 100049, China
}

\section{A R T I C L E I N F O}

\section{Article history:}

Received 13 September 2013

Received in revised form

20 December 2013

Accepted 21 December 2013

Available online 2 January 2014

\section{Keywords:}

Substituted polycyclic aromatic hydrocarbons

$\mathrm{A}^{2} / \mathrm{O}$ process

Biotransformation

Removal mechanism

\begin{abstract}
A B S T R A C T
Wastewater treatment plant (WWTP) effluent is the major source for substituted polycyclic aromatic hydrocarbons (SPAHs) to the receiving rivers, as well as the parent PAHs. Some of the SPAHs showed higher toxicities and levels than their parent PAHs. The occurrence and behavior of typical SPAHs were investigated in a representative biological WWTP in Beijing, China. Methyl PAHs (MPAHs) (149-221 ng/L in the influent; $29.6-56.3 \mathrm{ng} / \mathrm{L}$ in the effluent; 202-375 ng/g in the activated sludge), oxygenated PAHs (OPAHs) (139-155 ng/L; 69.9 -109 ng/L; 695-1533 ng/g) and PAHs (372-749 ng/L; 182-241 ng/L; 2402-3321 ng/g) existed, but nitrated PAHs (NPAHs) were not detected. 2-Methylnaphthalene, anthraquinone, 9fluorenone and 2-methylanthraquinone were the predominant SPAHs. OPAHs were deduced to be formed from PAHs especially during summer, based on the ratios variation and removal efficiencies of the two seasons, and the surplus mass in the outflows. Low molecular weight compounds (2-3 rings) might be mainly removed by mineralization/ transformation and adsorption in the anaerobic unit, and by volatilization in the aerobic unit. High molecular weight compounds (4-6 rings) might be mainly removed by adsorption in the anaerobic unit. The total outflows of SPAHs and PAHs were $66 \mathrm{~g} / \mathrm{d}$ in summer and $148 \mathrm{~g} / \mathrm{d}$ in winter from the WWTP to the receiving river. The percentage of OPAHs was higher in summer than in winter.
\end{abstract}

(c) 2013 Elsevier Ltd. All rights reserved.

\section{Introduction}

Effluent from wastewater treatment plants (WWTPs) in urban cities has been identified as the major direct source for organic pollutants entering the receiving rivers (Tian et al., 2012). A previous study has figured out that the WWTPs effluent was the main contributor for dissolved polycyclic aromatic hydrocarbons (PAHs) to the rivers in Beijing and Tianjin (Qi et al., 2013). Though PAHs originated from incomplete combustion and vehicle emission (Manoli and Samara, 1999), the contribution of direct atmospheric deposition to the rivers was only 7\% (Qi et al., 2013). In recent years, some typical substituted

\footnotetext{
* Corresponding author. Tel.: +8610 62849151; fax: +86 1062923558

E-mail address: jhqu@rcees.ac.cn (J. Qu).
} 
PAHs (SPAHs), including methyl PAHs (MPAHs), oxygenated PAHs (OPAHs) and nitrated PAHs (NPAHs) have been paid much attention due to their higher toxicities than PAHs, such as carcinogenicity, mutagenicity and allergic diseases (Tokiwa et al., 1986; Durant et al., 1996). Besides the similar sources to PAHs, NPAHs and OPAHs can also be formed from PAHs by photo-chemical oxidation in atmosphere with $\mathrm{NO}_{\mathrm{x}}, \mathrm{O}_{3}$ and $\mathrm{OH}$ (Bamford and Baker, 2003; Wang et al., 2007; Kojima et al., 2010), and OPAHs from biological transformation in soil with white rot fungi (Lundstedt et al., 2007; Haritash and Kaushik, 2009), respectively. Previous studies mainly focused on the pollution levels of SPAHs in the atmospheric and soil environment (Vincenti et al., 1996; Niederer, 1998; Lundstedt et al., 2007; Di Filippo et al., 2010). Our recent study demonstrated that WWTP effluent contributed 62-93\% PAHs and SPAHs (dissolved and absorbed phase) of the total input to the receiving rivers (Qiao et al.). Consequently, it is imperative to investigate this type of pollutant in the main direct source, WWTPs for a better understanding of their behaviors.

As is known that PAH is a type of ubiquitous pollutant in WWTPs (Pham and Proulx, 1997; Manoli and Samara, 1999; Busetti et al., 2006; Vogelsang et al., 2006). Previous studies have well documented the removal efficiencies and potential mechanisms of PAHs during biological treatment processes. The reduction of the low molecular weight (LMW) PAHs (33-100\%) was higher than the high molecular weight (HMW) PAHs (18-60\%) (Bergqvist et al., 2006). LMW PAHs were lost possibly due to biodegradation and volatilization and HMW PAHs due to adsorption (Manoli and Samara, 1999). Though PAHs may undergo photolysis and chemical degradation, microbiological degradation is the major degradation pathway (Haritash and Kaushik, 2009). PAHs do not only mineralize to $\mathrm{CO}_{2}, \mathrm{H}_{2} \mathrm{O}$ and $\mathrm{CH}_{4}$, but also can transform to OPAHs in the presence of laccase (Cañas et al., 2007). Anthraquinone is the main oxidation product of anthracene and can be accumulated (Haritash and Kaushik, 2009). However, until now, no literature has been reported the possible transformation from PAHs to OPAHs during a biological treatment process in WWTP.

In order to reduce the pollution levels of these targets in WWTP effluent, it is essential to understand the removal mechanisms of SPAHs and PAHs. Not only the pollutants in the effluent, but also in the dewatered sludge, should be paid severe attention to. The contents of SPAHs and PAHs in the sludge may be higher than in the effluent, due to their lipophilic property. Meanwhile, the transformation from PAHs to OPAHs may also occur. The disposal of the sewage sludge for land use may be harmful to the human health (Villar et al., 2009) by the accumulation of these toxic pollutants if they enter the drinking water sources and/or food chains (Beck et al., 1996). To the best of our knowledge, the removal mechanisms of OPAHs and NPAHs have also never been reported in water and sludge from a WWTP.

This work aimed (1) to investigate the occurrence of SPAHs in a WWTP; (2) to figure out the transformation from PAHs to OPAHs, a possible degradation pathway of PAHs besides mineralization; (3) to gain an insight of the removal mechanisms of SPAHs and PAHs during a biological wastewater treatment process; and (4) to primarily discuss the impact of SPAHs and PAHs from the WWTP to the receiving river.

\section{Materials and methods}

\subsection{Wastewater treatment process}

The studied WWTP, located in the northwest of Beijing, serves a population of 814000 and an area of $159.42 \mathrm{~km}^{2}$. The biological treatment of this plant contains two parallel processes, the anoxic - anaerobic - aerobic (inversed $\mathrm{A}^{2} / \mathrm{O}$ ) process and the anaerobic - anoxic - aerobic $\left(\mathrm{A}^{2} / \mathrm{O}\right)$ process (Fig. 1). The capacity of each process is $200000 \mathrm{~m}^{3}$ per day. The hydraulic retention times (HRTs) of the inversed $A^{2} / O$ process are $1.5 \mathrm{~h}, 2.5 \mathrm{~h}$ and $10.0 \mathrm{~h}$, and of the $\mathrm{A}^{2} / \mathrm{O}$ process are $1.5 \mathrm{~h}, 3 \mathrm{~h}$ and $10.8 \mathrm{~h}$, respectively. The total solid retention times (SRTs) are 6-7 $d$ for the inversed $A^{2} / O$ process and $20-25 d$ for the $A^{2} /$ O process.

\subsection{Sample collection and analytical procedure}

Samples were collected from the effluent of each unit ( $a, b, c$, $d$, ib, ic, id) of the secondary treatment process during summer (the non-heating season, July 2012), as signed in Fig. 1. Due to the frequent rainfall in this season, the day we chose was after several-day rainfall as a typical case (Table S1). $4 \mathrm{~L}$ water (W, dissolved phase) and sludge (S, absorbed phase) mixed samples were grabbed at each site at 10:00, 13:00 and 16:00. During winter (the heating season), the samples were collected on three separate days from February to March 2013, at 7 sampling sites (a, b, c, d, e, f, g) of the $A^{2} / O$ process. The days we sampled on in this season were during the dry weather condition, before which there was almost no snowfall (Table S1). Physical-chemical parameters of each sample are listed in Table S2. Sodium azide was added to each sample immediately after collection, in order to prevent microbial degradation. All samples were stored in darkness. The details of the pretreatment and instrument analysis procedure, quality assurance and quality control are given in the Supporting information.

\subsection{Chemicals and materials}

Thirteen individual SPAH standards, including 2methylnaphthalene (2-MN, in solid 100\%), 1-methylfluoran thene (1-MF, $10 \mu \mathrm{g} / \mathrm{mL}$ ), 2,6-dimethylnaphthalene (2,6-DMN, in solid 100\%), 3,6-dimethylphenanthrene (3,6-DMP, in solid $100 \%)$, 9-fluorenone (9-FL, in solid 100\%), anthraquinone (AQ $100 \mu \mathrm{g} / \mathrm{mL}$ ), 2-methylanthraquinone (2-MAQ in solid 99.0\%), benz[a]anthracene-7,12-dione (BA-7,12-D, $50 \mu \mathrm{g} / \mathrm{mL}$ ), 2nitrofluorene (2-NF, in solid 99.9\%), 9-nitroanthracene (9-NA, $100 \mu \mathrm{g} / \mathrm{mL}$ ), 3-nitrofluoranthene (3-NF, in solid 100\%), 1nitropyrene (1-NP, in solid 99.8\%), 7-nitrobenz[a]anthracene (7-NBA, $100 \mu \mathrm{g} / \mathrm{mL}$ ), and the sixteen USEPA priority PAHs, including naphthalene (Nap), acenaphthylene (Acy), acenaphthene (Ace), fluorene (Fluo), phenanthrene (Phe), anthracene (Ant), fluoranthene (Flua), pyrene (Pyr), benz[a] anthracene (BaA), chrysene (Chry), benzo[b]fluoranthene $(\mathrm{BbF})$, benzo[k]fluoranthene $(\mathrm{BkF})$, benzo[a]pyrene $(\mathrm{BaP})$, indeno[1,2,3-cd]pyrene (IcdP), dibenz[a,h]anthracene (DBA), and benzo[g,h,i]perylene (BghiP), in a mixture $(200 \mu \mathrm{g} / \mathrm{mL})$ were purchased from AccuStandard, Inc., New Haven, USA. 


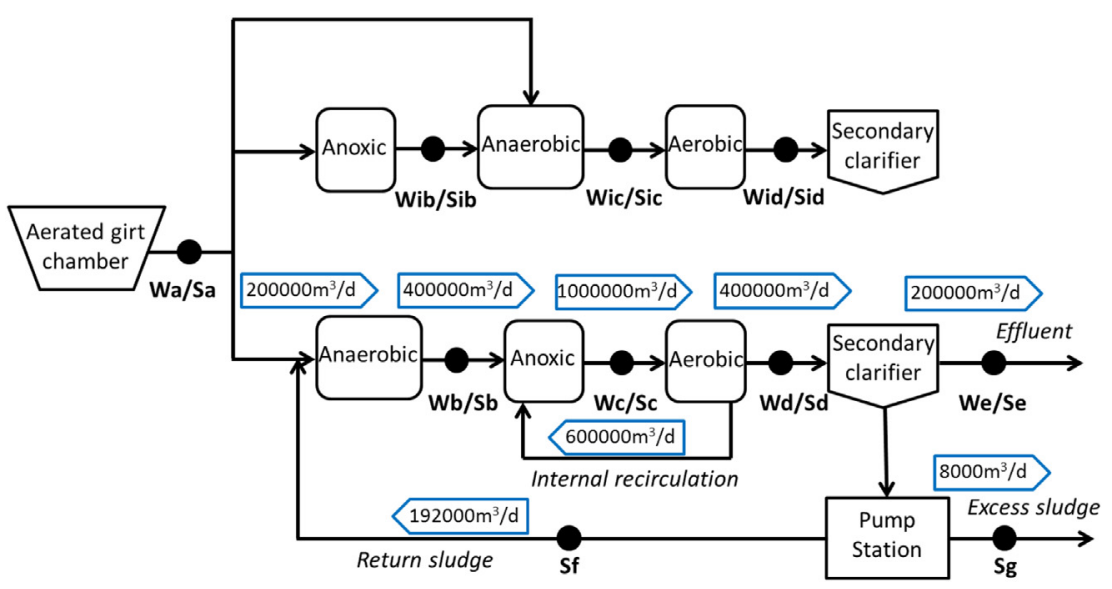

Fig. 1 - The biological wastewater treatment progress with sampling sites.

Internal standards for 2-fluorobiphenyl (2-FB, in solid > 96\%) and decachlorobiphenyl (PCB209) were obtained from Aldrich Chemical Co., Inc. (Gillingham, Dorset, UK). The physical-chemical properties of the 29 targets are listed in Table S3.

\subsection{Mass flow calculation}

To assess the mass balance of the target compounds during the wastewater treatment process, mass flow ( $F, g / d)$ was calculated as follows (Zeng et al., 2012).

$F=\left(C_{\text {dissolved }}+C_{\text {absorbed }} \times C_{\mathrm{TS}}\right) \times Q_{\text {water }} \times 10^{-6}$

where $C_{\text {dissolved }}, C_{\text {absorbed }}$ and $C_{\mathrm{TS}}$ represent the concentrations of the targets in the dissolved phase ( $\mathrm{ng} / \mathrm{L}$ ) samples, absorbed phase $(\mu \mathrm{g} / \mathrm{g})$ samples and total solids $(\mathrm{mg} / \mathrm{L})$ respectively; and $Q_{\text {water }}$ is the water flow $\left(\mathrm{m}^{3} / \mathrm{d}\right)$ in each treatment stage.

\section{Results and discussion}

\subsection{The occurrence of SPAHs and PAHs in the biological} wastewater treatment process

We classified the 13 SPAHs into 3 types based on different substituted group, encompassing MPAHs (2-MN, 2,6-DMN, 3,6-
DMP and 1-MF), OPAHs (9-FL, AQ 2-MAQ and BA-7,12-D) and NPAHs (2-NF, 9-NA, 3-NF, 1-NP and 7-NBA). The PAHs were divided into 2 groups on the basis of the target ring numbers, including the LMW PAHs (Nap, Acy, Ace, Fluo, Phe and Ant) and HMW PAHs (Flua, Pyr, BaA, Chry, BbF, BkF, Bap, IcdP, DBA and BghiP). To figure out the variation of all our targets during a secondary wastewater treatment process, two parallel processes of WWTP were studied, the inversed $\mathrm{A}^{2} / \mathrm{O}$ and $\mathrm{A}^{2} / \mathrm{O}$ process during summer. Targets were also determined in winter ( $\mathrm{A}^{2} / \mathrm{O}$ process) for the comparison of their behaviors with summer. The result showed no significant systematic differences of the measured concentrations either during the three sampling times of a day in summer, or during the three sampling days in winter (Table 1), but the sampling seasons exhibited significant impact (paired-samples t-test, $P<0.05$ ). This result was consistent with Manoli's study that only the sampling season but hours or days was a significant factor on the variability of PAHs concentrations in raw sewage (Manoli and Samara, 1999). Compared with $\mathrm{A}^{2} / \mathrm{O}$ process, no significant variation occurred in the concentrations of all the targets in the dissolved phase during the inversed $A^{2} / O$ process (independent sample t-test, $P>0.05)$, but significant in the absorbed phase (independent sample t-test, $P<0.05$ ). MPAH, OPAH and PAH targets existed in all the dissolved (ng/L) and absorbed (ng/g, d.w.) phase samples. However, no NPAH was detected, probably due to their photo-chemical

Table 1 - Concentrations of SPAH and PAH in water (W, dissolved phase, ng/L, SD $(n=3))$ and solid (S, absorbed phase, ng/ g, SD $(n=3))$ samples.

\begin{tabular}{|c|c|c|c|c|c|c|c|}
\hline & & $\sum \mathrm{MPAH}$ & $\sum \mathrm{OPAH}$ & $\sum \mathrm{SPAH}$ & $\sum \mathrm{LMW}$ PAH & $\sum \mathrm{HMW}$ PAH & $\sum \mathrm{PAH}$ \\
\hline \multirow[t]{6}{*}{ Summer } & W-influent & $149 \pm 40.1$ & $139 \pm 7.81$ & $288 \pm 33.7$ & $268 \pm 47.0$ & $104 \pm 9.65$ & $372 \pm 56.6$ \\
\hline & W-aerobic & $32.0 \pm 1.46$ & $109 \pm 2.66$ & $141 \pm 2.35$ & $118 \pm 4.69$ & $70.3 \pm 1.88$ & $188 \pm 3.24$ \\
\hline & W-aerobic-i & $29.6 \pm 4.31$ & $100 \pm 4.39$ & $130 \pm 4.49$ & $111 \pm 9.59$ & $70.6 \pm 0.27$ & $182 \pm 9.35$ \\
\hline & S-influent & $454 \pm 171$ & $1073 \pm 375$ & $1526 \pm 545$ & $1348 \pm 450$ & $2912 \pm 436$ & $4260 \pm 866$ \\
\hline & S-aerobic & $202 \pm 9.00$ & $695 \pm 63.8$ & $897 \pm 72.5$ & $416 \pm 15.3$ & $1986 \pm 52.5$ & $2402 \pm 67.0$ \\
\hline & S-aerobic-i & $250 \pm 16.1$ & $1533 \pm 196$ & $1783 \pm 212$ & $481 \pm 4.91$ & $2068 \pm 30.8$ & $2549 \pm 33.0$ \\
\hline \multirow[t]{5}{*}{ Winter } & W-influent & $221 \pm 15.2$ & $155 \pm 19.4$ & $385 \pm 2.16$ & $595 \pm 67.1$ & $146 \pm 13.3$ & $749 \pm 69.9$ \\
\hline & W-effluent & $56.3 \pm 12.8$ & $69.9 \pm 5.58$ & $126 \pm 15.2$ & $191 \pm 42.0$ & $50.2 \pm 3.04$ & $241 \pm 44.8$ \\
\hline & S-influent & $983 \pm 92.2$ & $1117 \pm 162$ & $2100 \pm 142$ & $2686 \pm 577$ & $3095 \pm 243$ & $5781 \pm 622$ \\
\hline & S-aerobic & $375 \pm 22.0$ & $868 \pm 91.9$ & $1243 \pm 79.3$ & $1028 \pm 65.3$ & $2292 \pm 194$ & $3321 \pm 248$ \\
\hline & S-effluent & $17509 \pm 2058$ & $15272 \pm 2167$ & $32781 \pm 4225$ & $62970 \pm 7211$ & $31950 \pm 4072$ & $94920 \pm 11283$ \\
\hline
\end{tabular}


Table 2 - Concentrations of PAHs in the influent of other WWTPs.

\begin{tabular}{|c|c|c|c|c|c|}
\hline Country & Sampling site & Sampling date & $\mathrm{PAH}(\mu \mathrm{g} / \mathrm{L})$ & 2-MN (ng/L) & 2,6-DMN (ng/L) \\
\hline Canada (Pham and Proulx, 1997) & Montreal Urban Community & July-Oct. 1993 & 4.18 & 83 & 55 \\
\hline Jordan (Jiries et al., 2000) & Karak, 2 WWTPs & Oct. 1997 & $1.17-1.22$ & - & - \\
\hline Italy (Busetti et al., 2006) & Venice, Fusina WWTP & Oct. 2002 & 2.11 & - & - \\
\hline Italy (Fatone et al., 2011) & 5 WWTPs & $2005-2008$ & $0.32-1.54$ & - & - \\
\hline Norway (Vogelsang et al., 2006) & 5 WWTPs & Spring \& autumn, 2002 & $0.2-1.3$ & - & - \\
\hline \multirow[t]{2}{*}{ China (Tian et al., 2012) } & Tai'an WWTP & May 2008 & 1.15 & - & - \\
\hline & & Nov. 2008 & 1.16 & - & - \\
\hline Sweden (Bergqvist et al., 2006) & Umea WWTP & Oct. \& Nov. 2001 & - & 130 & 36 \\
\hline Lithuania (Bergqvist et al., 2006) & Siauliai WWTP & Oct. \& Nov. 2001 & - & 50 & 54 \\
\hline
\end{tabular}

transformation (Chapman et al., 1966; Fan et al., 1996) or a lower concentration than the method detection limits. The phenomenon was similar to our previous study (Qiao et al., 2013). As to the influence of the rainfall, the detected daily treatment capacities were $220000 \mathrm{~m}^{3}$ on the sampling day in summer and $190000 \mathrm{~m}^{3}$ in winter, with an average of $200000 \mathrm{~m}^{3} / \mathrm{d}$. The variations of the target concentrations between the detected and average daily capacity were not significant (paired-samples t-test, $P>0.05$ ), indicating that the rainfall prior to the sampling day in summer was not a main impact factor.

\subsubsection{Concentrations of SPAHs and PAHs in the dissolved phase samples}

In the dissolved phase of the influent samples (Wa) during summer, the concentrations of $\sum$ SPAHs $(288 \pm 33.7 \mathrm{ng} / \mathrm{L})$ and $\sum$ PAHs (372 $\left.\pm 56.6 \mathrm{ng} / \mathrm{L}\right)$ were lower than those (385 $\pm 2.16 \mathrm{ng} /$ $\mathrm{L}$ for SPAHs and $749 \pm 69.9 \mathrm{ng} / \mathrm{L}$ for PAHs) during winter (Table 1). The result of PAHs was corresponding with Qi et al.'s study, probably resulting from the coal burnings in winter (Qi et al., 2011) and the higher atmospheric deposition in the cold period (Wang et al., 2011). Compared with the influent of WWTPs in other cities of the world (Table 2), PAHs were present at lower concentrations in this work $(0.37 \pm 0.06 \mu \mathrm{g} / \mathrm{L}$ in summer and $0.75 \pm 0.07 \mu \mathrm{g} / \mathrm{L}$ in winter). However, there is a lack of study on the comparison of the concentrations at different temperatures such as summer and winter, which may influence the degradation, volatilization, and adsorption. Generally speaking, the release of the PAHs to the studied WWTP in Beijing was less severe than Montreal Urban Community WWTP in Canada, a WWTP in Tai'an, China and WWTPs in most of the European countries. During the treatment process, the concentrations of MPAHs were lower than OPAHs (Table S4). The higher volatility or biodegradation of MPAHs during the biological treatment might result in the lower concentrations. The higher concentrations of LMW PAHs than HMW PAHs was probably due to the lower $\log K_{\text {ow }}$ value of LMW PAHs than HMW PAHs.

From the aspect of the individual SPAHs (Fig. 2 and Table S4), the concentrations of 2-MN and $\mathrm{AQ}$ were much higher or similar to the other target compounds in the same group. So, in this section, 2-MN with the corresponding 2,6-DMN, and AQ with 2-MAQ were taken as examples of MPAHs and OPAHs for comparisons with the corresponding PAHs. The concentrations of 2-MN and 2,6-DMN were $136 \pm 38.3 \mathrm{ng} / \mathrm{L}$ and $6.65 \pm 1.31 \mathrm{ng} / \mathrm{L}$ in the influent in summer, and $204 \pm 13.6 \mathrm{ng} / \mathrm{L}$ and $10.7 \pm 1.36 \mathrm{ng} / \mathrm{L}$ in winter. The pollution levels of 2-MN were higher and 2,6-DMN were lower in the influent of WWTPs in the present study than those in Montreal Urban Community WWTP, Umea WWTP and Siauliai WWTP (Table 2), possibly resulting from the different sources of the raw wastewater. The concentrations of individual MPAHs were lower than their corresponding PAHs (Table S5) through the treatment process, both during summer and winter (Fig. 2a). As to OPAHs (Fig. 2c), AQ (28.4-66.2 ng/L) occurred at higher concentrations than 2MAQ (8.79-19.5 ng/L). Compared with these OPAHs, the concentrations of the parent PAH, Ant (1.96-9.22 ng/L) were lower (Table S5), the same as our previous study (Qiao et al., 2013). Other MPAHs and OPAH to the corresponding PAHs presented the similar phenomenon.

\subsubsection{Concentrations of SPAHs and PAHs in the absorbed phase samples}

In the particles of the influent (Sa) (Table 1), $\sum$ SPAHs and $\sum$ PAHs during summer (1526 $\pm 545 \mathrm{ng} / \mathrm{g}$ and $\left.4260 \pm 866 \mathrm{ng} / \mathrm{g}\right)$ were present at a little lower concentrations than winter $(2100 \pm 142 \mathrm{ng} / \mathrm{g}$ and $5781 \pm 622 \mathrm{ng} / \mathrm{g})$. The concentrations of all the targets through the inversed $\mathrm{A}^{2} / \mathrm{O}$ process were a little higher than the $\mathrm{A}^{2} / \mathrm{O}$ process in summer. The concentrations of PAHs and SPAHs in the absorbed phase of the effluent samples were extremely higher than in other absorbed phase samples, which might result from a larger surface area and a higher adsorption capacity of the suspended particles in the effluent than those in the influent and sludge during the process.

In the absorbed phase samples but the effluent particles, the concentrations of 2-MN (79.5-734 ng/g) were higher than 2,6-DMN (23.5-157 ng/g), and relatively the same with Nap (75.2-571 ng/g) (Fig. 2b). As to OPAHs, the concentrations of 2MAQ (368-1226 ng/g) were higher than AQ 137-271 ng/g, different from in the dissolved phase samples. The results showed that 2-MAQ was the dominant OPAHs compound in the absorbed phase samples, which might result from a higher $\log K_{\text {ow }}$ value of 2-MAQ than AQ or a possible transformation from relevant compounds through the biological transformation (Cañas et al., 2007; Haritash and Kaushik, 2009). Compared with the parent PAHs described in Fig. $2 d$, the concentrations of $\mathrm{AQ}$ and 2-MAQ were higher than Ant (58.6-161 ng/g). The $\log K_{\text {ow }}$ values of OPAHs were lower than their corresponding parent PAHs, but the concentrations of $\mathrm{AQ}$ and 2-MAQ were relatively the same or higher than Ant, indicating the higher pollution levels of OPAHs than PAHs in the absorbed phase samples. 


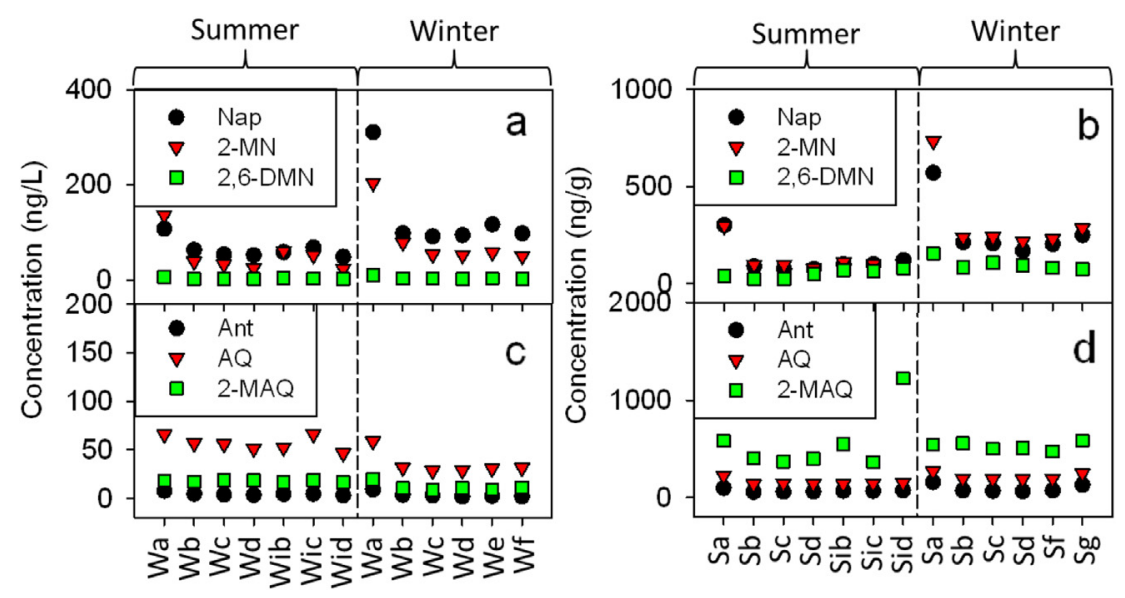

Fig. 2 - Comparison of the Nap and Ant to their corresponding SPAHs: the concentrations of the targets in the water (W, dissolved phase) and solid ( $\mathrm{S}$, absorbed phase) samples along the treatment process.

3.2. The relationships between the SPAHs and the corresponding PAHs for indicating the possible SPAHs formation

It has been reported that the possible formations of OPAHs could be analyzed based on the ratios of OPAHs to the corresponding PAHs (Walgraeve et al., 2010). The SPAHs to PAHs ratios were calculated in the dissolved and absorbed phase samples in the influent, anaerobic, anoxic and aerobic unit both during summer and winter (Fig. 3). In general, the ratios of OPAHs to PAHs were higher than those of MPAHs to PAHs both in the dissolved and absorbed phase samples.

For OPAHs, in the dissolved phase samples, AQ to Ant ratios (6.37-15.08) were the highest among the 4 sets of OPAHs (1.07-5.42) (Table S6). As the treatment process went on, from sampling site a (influent) to d (aerobic unit), the values of AQ/ Ant increased during the both seasons. Previous studies demonstrated that Ant could be biologically transformed to AQ (Cañas et al., 2007; Lundstedt et al., 2007; Wu et al., 2010). So the result of the present study suggested that the biotransformation from Ant to AQ might occur along the process. It could also be noticed from Fig. 3 that the ratios were higher in summer than in winter. The higher temperature in summer probably improved the biological transformation process. The direct evidence of the biological transformation should be proved by simulate experiment in the laboratory in our further studies. The ratios of the other OPAHs to PAHs showed the similar phenomenon, but less significant than AQ to Ant. By contrast, regarding MPAHs to PAHs ratios, no significant variation occurred, demonstrating the similar degradation process of MPAHs and the corresponding PAHs.

In the absorbed phase samples, the ratios of 2-MAQ to Ant (3.38-7.63) were higher than AQ to Ant (1.68-2.83), probably indicating an easier formation of 2-MAQ than AQ in the sludge. The values of 2-MAQ/Ant and $\mathrm{AQ} / \mathrm{Ant}$ in the absorbed phase of the influent were higher during summer than winter as in the dissolved phase samples. In the sludge samples, the values of 2-MAQ/Ant and AQ/Ant increased along the treatment process, and a little more rapidly during winter. This could be explained by the different adsorption ability with different temperature. The results illustrated the possible transformation occurred along the treatment process, in accordance with the study of Cañas et al. (2007) in the presence of laccase. For MPAHs, as in the dissolved phase samples, the insignificant variation suggested that the source and fate of MPAHs and PAHs in the WWTP were relatively the same.
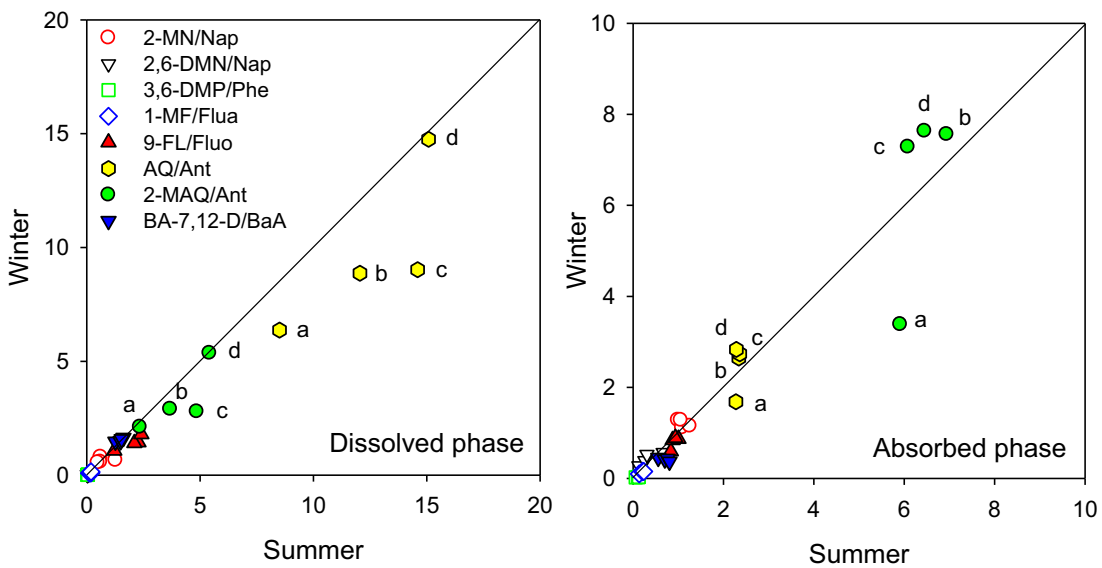

Fig. 3 - Ratios of SPAHs to PAHs both in summer and winter. 


\subsection{Mass flow analysis for indicating the removal mechanisms of SPAHs and PAHs}

The average total mass flows of all the targets along the entire secondary biological treatment process were calculated in the both seasons (Fig. 4), in order to understand the removal mechanisms of the target compounds during each unit of the treatment.

On the whole, the mass flows in the absorbed phase $(318 \pm 38 \mathrm{~g} / \mathrm{d})$ of the influent were a little higher than those in the dissolved phase $(179 \pm 14 \mathrm{~g} / \mathrm{d})$. After entering the secondary treatment process, more than $97 \%$ of the target compounds absorbed onto the sludge, indicating that absorption was probably the main removal mechanism for the total SPAHs and PAHs. Additionally, the solid-water partition coefficients $\left(K_{d}\right)$ of individual targets were calculated (Table S7). In general, the $K_{d}$ values increased along the treatment process, demonstrating again that the importance of adsorption on the targets removal. The $K_{d}$ values were higher in winter than in summer in each unit of the treatment process (except the influent), probably caused by the stronger adsorption with lower temperature.

Along the treatment process, a large amount of the targets returned from the aerobic unit to the anoxic unit and from the secondary clarifier to the anaerobic unit with the return sludge. Thus, after the whole biological treatment, only a small amount of the targets discharged out of the WWTP. The masses of the targets were much lower in the effluent (70 $\pm 6 \mathrm{~g} / \mathrm{d}$ in dissolved phase and $74 \pm 12 \mathrm{~g} / \mathrm{d}$ in absorbed phase, accounting for $29 \%$ of the total input) than in the excess sludge (339 $\pm 14 \mathrm{~g} / \mathrm{d}$, accounting for 68\%). Regarding PAHs, according to the service population, the total output was $0.46 \mathrm{mg} / \mathrm{d}$ by per capita in the studied WWTP, similar to the WWTP in Thessaloniki (0.36 mg/d) (Manoli and Samara, 1999).

The final mass fractions of the effluent (dissolved and absorbed phase) and excess sludge (absorbed phase) to the total initial loadings (100\%) were also investigated in the both seasons (Fig. 5). We divided all the target compounds into six groups in this section, based on their different ring numbers, the LMW MPAHs (2-MN, 2,6-DMN and 3,6-DMP), HMW MPAHs (1-MF), LMW OPAHs (9-FL, AQ and 2-MAQ), HMW OPAHs (BA7,12-D), LMW PAHs and HMW PAHs. The LMW MPAHs and LMW PAHs behaved differently with the HMW ones (Fig. 5a, b, $i, j)$. The total outflows of LMW MPAHs (46\% and 63\%) and LMW PAHs (60\% and $83 \%)$ were lower than the inflow in the both seasons. Meanwhile, the loss percentages in summer ( $54 \%$ for LMW MPAH and 40\% for LMW PAH) were higher than in winter (37\% for LMW MPAH and 17\% for LMW PAH). The loss of the targets was corresponding to the biodegradation/ transformation and volatilization. Thus, the LMW MPAHs and LMW PAHs were mainly removed by these two processes. Regarding LMW OPAHs, the output percentage was higher than the input in summer (140\%) (Fig. 5e), and relatively the same in winter (97\%) (Fig. 5f). The surplus OPAHs in the outflows might be another evidence for the formation of OPAHs. As to the HMW targets, the output percentages were relatively similar with the input in winter (Fig. 5d, h, l) and higher than the input in summer (Fig. 5c, g, k). The surplus HMW targets possibly came from the residues of the targets in the activated sludge. The total SRTs were 20-25 d, might introduce the targets, especially those with higher $\log K_{\text {ow }}$ values reside in the activated sludge before our sampling.

The removal efficiency refers to the reduced percentage of the targets in the dissolved phase, for further evaluating the removal mechanisms through the biological treatment process (Fig. 6). The LMW MPAHs and LMW PAHs showed higher removal efficiencies. The result of the PAHs was consistent with other research that the LMW PAHs could be more easily removed than the HMW PAHs from the biological treatment process, probably due to the different removal mechanisms that the HMW PAHs were prone to absorbed on the sludge (Manoli and Samara, 1999). Thus, the removal efficiency of the LMW MPAHs and LMW PAHs should be higher during summer as a result of the easier biodegradation and volatilization with higher temperature (Table S2). However, the removal efficiency in summer was similar to or a little lower than in winter, indicating that there must be other process, such as adsorption which could be improved with lower temperature (Ren et al., 2007, 2011). Compared with summer, the removal efficiencies of LMW OPAHs and HMW compounds (HMW MPAH, HMW OPAH and HMW PAH) were much higher in winter. As discussed above, lower temperature might enhance the adsorption resulting in a higher removal efficiency of HMW compounds in winter, which was a significant evidence for the adsorption removal mechanism of those with higher $\log K_{\text {ow }}$ values (see individual targets removal efficiencies in Fig. S1). The removal mechanism of LMW OPAHs was probably not the same with HMW compounds, due to their lower $\log K_{\text {ow }}$ value. They should be removed both by biodegradation and adsorption as LMW MPAHs and LMW PAHs. The difference in the removal efficiency suggested that as the LMW OPAHs biodegraded, they might be formed from PAHs, particularly with higher temperature during the treatment process.

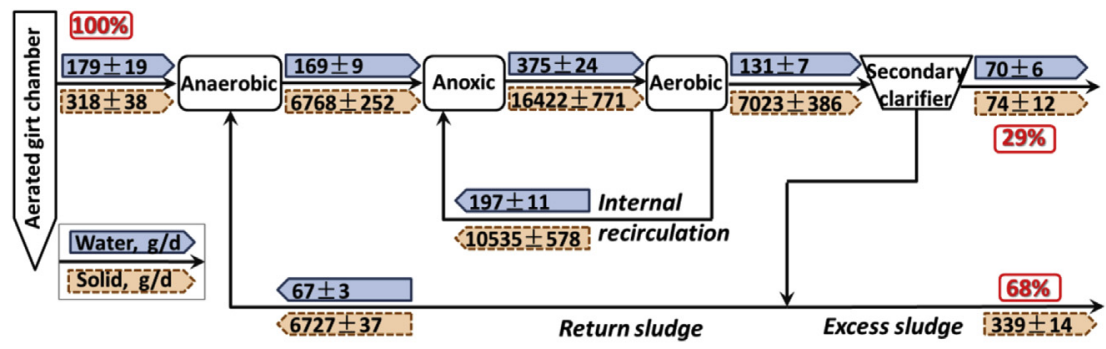

Fig. 4 - Total mass flows (g/d) of SPAHs and PAHs during the treatment process and the mass fractions discharged from the WWTP in effluent and dewatered sludge to the total initial mass loading $(100 \%)$. 

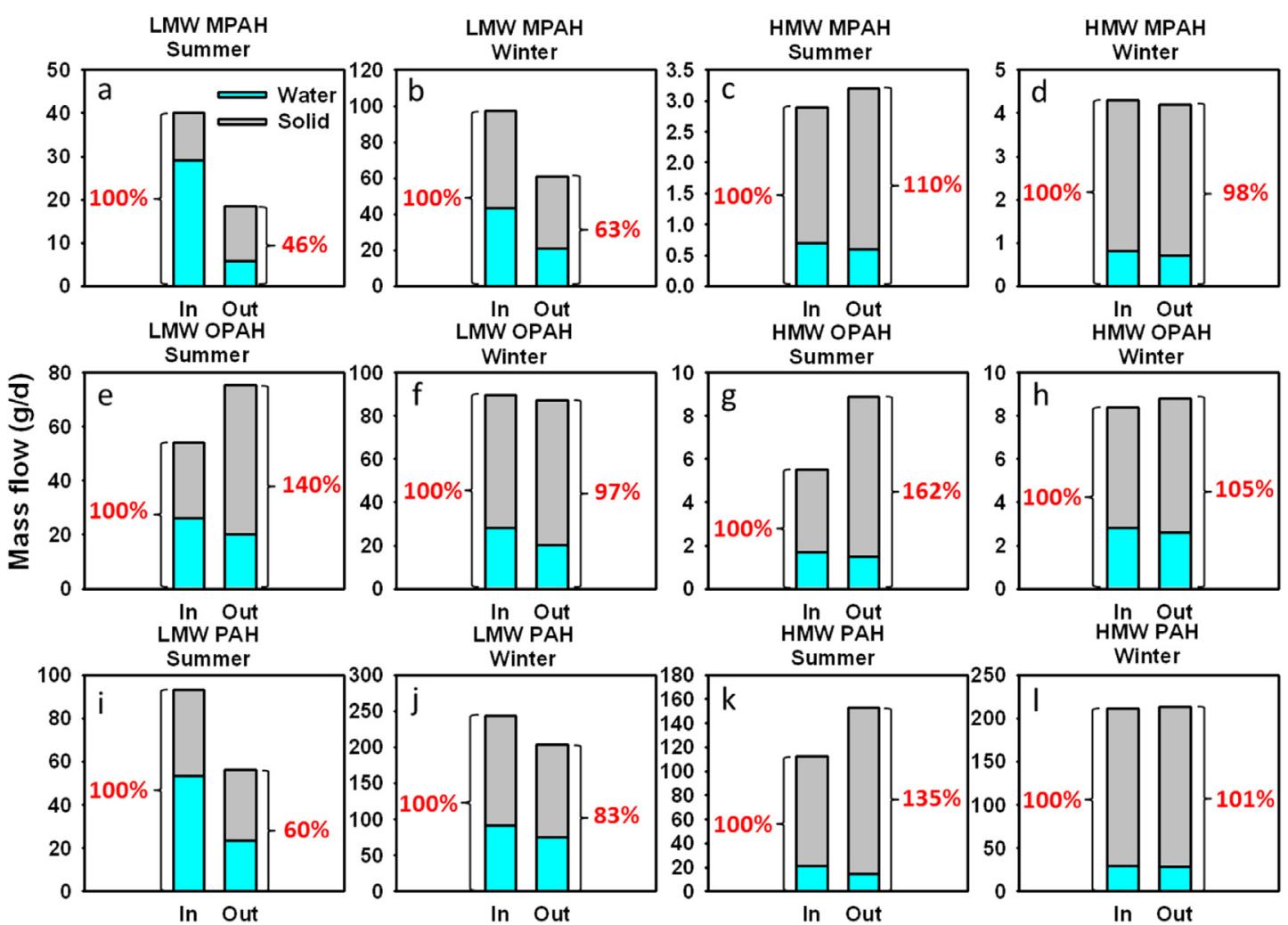

Fig. 5 - Input and output mass flows of MPAH, OPAH and PAH: the water and solid of the input refer to the water samples and particulate samples, and of the output refer to the effluent samples (water and particulate) and sludge samples.

For individual unit, the six groups of targets were mainly removed in the anaerobic unit with an average value of $29.2 \%$ in summer and $55.8 \%$ in winter (Fig. S2). Whereas in the anoxic and aerobic unit in summer and winter, the average changes ranged from $3.3 \%$ to $5.4 \%$. In summer, the removal of LMW MPAHs (70.3\%) and LMW PAHs (44.9\%) were mainly in the anaerobic unit, probably by biodegradation/transformation and adsorption. The volatilization might happen in the aerobic unit due to the aeration. As to LMW OPAHs and HMW target compounds, the removals in each unit were relatively

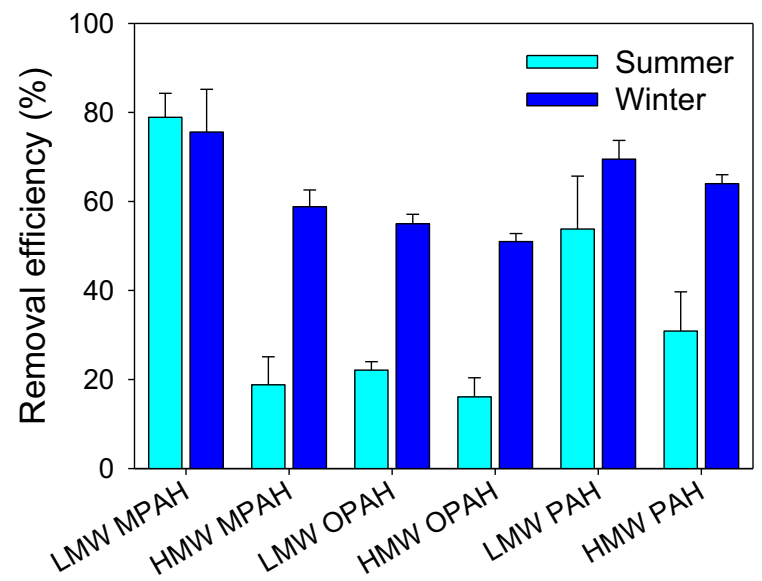

Fig. 6 - Removal efficiency of individual target group both in summer and winter. low. As figured out in the above paragraph, the transformation from PAHs and lower adsorption ability might influence the mass changes of LMW OPAHs and HMW targets, respectively. In winter, the majority targets were removed in the anaerobic unit by adsorption and biodegradation/transformation.

\subsection{The mass fractions of SPAHs and PAHs release to the rivers}

The total output mass flows of all the targets releasing to the receiving river were $66 \mathrm{~g} / \mathrm{d}$ (dissolved phase) in summer and $148 \mathrm{~g} / \mathrm{d}$ (dissolved and absorbed phase) in winter from the WWTP. As demonstrated in another study of ours, the WWTP effluent was the main contributor to the rivers. The investigated WWTP in this study contributed $13 \%$ in summer and $17 \%$ in winter SPAHs and PAHs of the total input to the Wenyu River and North Canal, which was the third highest contributor among the 4 major WWTPs in Beijing (Qiao et al.). Additionally, the percentages of OPAHs to all the targets in the total outflow were higher in summer (33\%) than in winter (15.4\%); while MPAHs and PAHs were lower (Fig. S3). Thus, the possible biological formation of OPAHs in WWTP might introduce more OPAHs to the receiving river with higher temperature.

\section{Conclusions}

This study investigated the occurrence and removal mechanisms of SPAHs and PAHs in a representative biological 
WWTP in Beijing, China. The 4 MPAHs (149-221 ng/L in the influent; $29.6-56.3 \mathrm{ng} / \mathrm{L}$ in the effluent; $202-375 \mathrm{ng} / \mathrm{g}$ in the activated sludge), 4 OPAHs (139-155 ng/L; 69.9-109 ng/L; 695-1533 ng/g) and 16 PAHs (372-749 ng/L; 182-241 ng/L; 2402-3321 ng/g) all existed, but the 5 NPAHs did not detected. 2-MN, 9-FL, AQ and 2-MAQ were the predominant SPAHs. The concentrations of 9-FL, AQ, 2-MAQ and BA-7,12-D were higher than $\mathrm{Fl}$, Ant and $\mathrm{BaA}$, especially in the dissolve phase samples.

The removal mechanisms of the targets were predicted. During the treatment process, LMW compounds might be mainly removed by mineralization/transformation and adsorption in the anaerobic unit, and by volatilization in the aerobic unit. HMW compounds might be mainly removed by adsorption to the sludge in the anaerobic unit. OPAHs were deduced to be formed from PAHs especially in summer with higher temperature, based on the seasonal variations of OPAHs to PAHs ratios, the surplus masses in the outflow and OPAHs removal efficiencies. The daily releasing of SPAHs and PAHs were $66 \mathrm{~g} / \mathrm{d}$ in summer and $148 \mathrm{~g} / \mathrm{d}$ in winter from the WWTP to the receiving river. The mass percentage of OPAHs to all the targets was higher in summer than in winter, while MPAHs and PAHs were lower. To reduce the pollution of OPAHs, the microbiological transformation from PAHs to OPAHs should be demonstrated and investigated. Therefore, in our future study, simulated experiment as the biological treatment process will be conducted.

\section{Acknowledgments}

The authors gratefully acknowledge Rong Qi (RCEES) and operators of the investigated WWTP for their assistance of the sampling collection. This work was supported by National Natural Science Foundation of China (Grant No. 51138006) and National Natural Science Foundation of China (Grant No. 41203069).

\section{Appendix A. Supplementary data}

Supplementary data related to this article can be found at http://dx.doi.org/10.1016/j.watres.2013.12.032.

\section{RE F E R E N C E S}

Bamford, H.A., Baker, J.E., 2003. Nitro-polycyclic aromatic hydrocarbon concentrations and sources in urban and suburban atmospheres of the Mid-Atlantic region. Atmos. Environ. 37 (15), 2077-2091.

Beck, A.J., Johnson, D.L., Jones, K.C., 1996. The form and bioavailability of non-ionic organic chemicals in sewage sludge-amended agricultural soils. Sci. Total Environ. 185 (1-3), 125-149.

Bergqvist, P.A., Augulyte, L., Jurjonienè, V., 2006. PAH and PCB removal efficiencies in Umeå (Sweden) and Šiauliai (Lithuania) municipal wastewater treatment plants. Water Air Soil Pollut. 175 (1-4), 291-303.

Busetti, F., Heitz, A., Cuomo, M., Badoer, S., Traverso, P., 2006. Determination of sixteen polycyclic aromatic hydrocarbons in aqueous and solid samples from an Italian wastewater treatment plant. J. Chromatogr. 1102 (1-2), 104-115.

Cañas, A.I., Alcalde, M., Plou, F., Martínez, M.J., Martínez, Á.T., Camarero, S., 2007. Transformation of polycyclic aromatic hydrocarbons by laccase is strongly enhanced by phenolic compounds present in soil. Environ. Sci. Technol. 41 (8), $2964-2971$.

Chapman, O.L., Heckert, D.C., Reasoner, J.W., Thackaberry, S.P., 1966. Photochemical studies on 9-nitroanthracene. J. Am. Chem. Soc. 88 (23), 5550-5554.

Di Filippo, P., Riccardi, C., Pomata, D., Gariazzo, C., Buiarelli, F., 2010. Seasonal abundance of particle-phase organic pollutants in an urban/industrial atmosphere. Water Air Soil Pollut. 211 (1), 231-250.

Durant, J.L., Busby Jr., W.F., Lafleur, A.L., Penman, B.W., Crespi, C.L., 1996. Human cell mutagenicity of oxygenated, nitrated and unsubstituted polycyclic aromatic hydrocarbons associated with urban aerosols. Mutat. Res.-Genet. Toxicol. 371 (3-4), 123-157.

Fan, Z.H., Kamens, R.M., Hu, J.X., Zhang, J.B., McDow, S., 1996. Photostability of nitro polycyclic aromatic hydrocarbons on combustion soot particles in sunlight. Environ. Sci. Technol. 30 (4), 1358-1364.

Fatone, F., Di Fabio, S., Bolzonella, D., Cecchi, F., 2011. Fate of aromatic hydrocarbons in Italian municipal wastewater systems: an overview of wastewater treatment using conventional activated-sludge processes (CASP) and membrane bioreactors (MBRs). Water Res. 45 (1), 93-104.

Haritash, A.K., Kaushik, C.P., 2009. Biodegradation aspects of polycyclic aromatic hydrocarbons (PAHs): a review. J. Hazard. Mater. 169 (1-3), 1-15.

Jiries, A., Hussain, H., Lintelmann, J., 2000. Determination of polycyclic aromatic hydrocarbons in wastewater, sediments, sludge and Plants in Karak Province, Jordan. Water Air Soil Pollut. 121 (1-4), 217-228.

Kojima, Y., Inazu, K., Hisamatsu, Y., Okochi, H., Baba, T., Nagoya, T., 2010. Influence of secondary formation on atmospheric occurrences of oxygenated polycyclic aromatic hydrocarbons in airborne particles. Atmos. Environ. 44 (24), 2873-2880.

Lundstedt, S., White, P.A., Lemieux, C.L., Lynes, K.D., Lambert, L.B., Oberg, L., Haglund, P., Tysklind, M., 2007. Sources, fate, and toxic hazards of oxygenated polycyclic aromatic hydrocarbons (PAHs) at PAH-contaminated sites. Ambio 36 (6), 475-485.

Manoli, E., Samara, C., 1999. Occurrence and mass balance of polycyclic aromatic hydrocarbons in the Thessaloniki sewage treatment plant. J. Environ. Qual. 28 (1), 176-187.

Niederer, M., 1998. Determination of polycyclic aromatic hydrocarbons and substitutes (nitro-, oxy-PAHs) in urban soil and airborne particulate by GC-MS and NCI-MS/MS. Environ. Sci. Pollut. Res. 5 (4), 209-216.

Pham, T.T., Proulx, S., 1997. PCBs and PAHs in the Montreal Urban Community (Quebec, Canada) wastewater treatment plant and in the effluent plume in the St Lawrence River. Water Res. 31 (8), 1887-1896.

Qi, W., Liu, H., Pernet-Coudrier, B., Qu, J., 2013. Polycyclic aromatic hydrocarbons in wastewater, WWTPs effluents and in the recipient waters of Beijing, China. Environ. Sci. Pollut. Res. 20 (6), 4254-4260.

Qi, W., Liu, H., Qu, J., Hu, C., Lan, H., Berg, M., Ren, H., Xu, W., 2011. Polycyclic aromatic hydrocarbons in effluents from wastewater treatment plants and receiving streams in Tianjin, China. Environ. Monit. Assess. 177 (1-4), 467-480.

Qiao, M., Qi, W., Liu, H., Qu, J., Oxygenated, nitrated, methyl and parent polycyclic aromatic hydrocarbons in rivers of Haihe River System, China: occurrence, possible formation, source and fate in a water-shortage area. (Unpublished results). 
Qiao, M., Qi, W., Liu, H., Qu, J., 2013. Simultaneous determination of typical substituted and parent polycyclic aromatic hydrocarbons in water and solid matrix by gas chromatography-mass spectrometry. J. Chromatogr. 1291, 129-136.

Ren, R., Li, K., Zhang, C., Liu, D., Sun, J., 2011. Biosorption of tetradecyl benzyl dimethyl ammonium chloride on activated sludge: kinetic, thermodynamic and reaction mechanisms. Bioresour. Technol. 102 (4), 3799-3804.

Ren, Y.X., Nakano, K., Nomura, M., Chiba, N., Nishimura, O., 2007. A thermodynamic analysis on adsorption of estrogens in activated sludge process. Water Res. 41 (11), 2341-2348.

Tian, W., Bai, J., Liu, K., Sun, H., Zhao, Y., 2012. Occurrence and removal of polycyclic aromatic hydrocarbons in the wastewater treatment process. Ecotoxicol. Environ. Saf. 82 (0), $1-7$.

Tokiwa, H., Ohnishi, Y., Rosenkranz, H.S., 1986. Mutagenicity and carcinogenicity of nitroarenes and their sources in the environment. Crit. Rev. Toxicol. 17 (1), 23-58.

Villar, P., Villar, M., Callejon, M., Perez, J.L., Jimenez, J.C., Alonso, E., Guiraum, A., 2009. Evolution of polycyclic aromatic hydrocarbons (PAHs) and heavy metals in sludge samples from conventional activated sludge wastewater treatment plants. Environmetrics 20 (5), 561-574.

Vincenti, M., Minero, C., Pelizzetti, E., Fontana, M., Maria, R.D., 1996. Sub-parts-per-billion determination of nitrosubstituted polynuclear aromatic hydrocarbons in airborne particulate matter and soil by electron capture-tandem mass spectrometry. J. Am. Soc. Mass Spectrom. 7 (12), 1255-1265.

Vogelsang, C., Grung, M., Jantsch, T.G., Tollefsen, K.E., Liltved, H., 2006. Occurrence and removal of selected organic micropollutants at mechanical, chemical and advanced wastewater treatment plants in Norway. Water Res. 40 (19), 3559-3570.

Walgraeve, C., Demeestere, K., Dewulf, J., Zimmermann, R., Van Langenhove, H., 2010. Oxygenated polycyclic aromatic hydrocarbons in atmospheric particulate matter: molecular characterization and occurrence. Atmos. Environ. 44 (15), 1831-1846.

Wang, L., Atkinson, R., Arey, J., 2007. Formation of 9,10phenanthrenequinone by atmospheric gas-phase reactions of phenanthrene. Atmos. Environ. 41 (10), 2025-2035.

Wang, W., Massey Simonich, S.L., Giri, B., Xue, M., Zhao, J., Chen, S., Shen, H., Shen, G., Wang, R., Cao, J., Tao, S., 2011. Spatial distribution and seasonal variation of atmospheric bulk deposition of polycyclic aromatic hydrocarbons in Beijing-Tianjin region, North China. Environ. Pollut. 159 (1), 287-293.

Wu, Y.R., Luo, Z.H., Vrijmoed, L.L.P., 2010. Biodegradation of anthracene and benz[a]anthracene by two Fusarium solani strains isolated from mangrove sediments. Bioresour. Technol. 101 (24), 9666-9672.

Zeng, L., Li, H., Wang, T., Gao, Y., Xiao, K., Du, Y., Wang, Y., Jiang, G., 2012. Behavior, fate, and mass loading of short chain chlorinated paraffins in an advanced municipal sewage treatment plant. Environ. Sci. Technol. 47 (2), 732-740. 